\title{
GEOMATICS CONTRIBUTION TO ROAD NETWORK CHARACTERIZATION CASE STUDY: BATNA CITY
}

\author{
Merdassi ABDELMOUMENE* \\ Laboratory LRNAT, University of Batna -02, Mustapha Ben Boulaid, Algeria, \\ e-mail: merdaci.sig@gmail.com \\ Kalla MAHDI \\ Laboratory LRNAT, University of Batna-2, Mustapha Ben Boulaid, Algeria, \\ e-mail: m_kalla1@yahoo.fr
}

\begin{abstract}
Citation: Abdelmoumene, M., \& Mahdi, K. (2020). Geomatics Contribution to Road Network Characterization Case Study: Batna City. Analele Universităţii din Oradea, Seria Geografie, 30(2), 157-156. https://doi.org/10.30892/auog.302105-817
\end{abstract}

\begin{abstract}
The city of Batna is an important crossroads between coastal cities and the far south. It is also an axis linking East to West across the highlands due to its valuable geographical location and its high demographic increase. As a result, traffic flow problems related mainly to the growing vehicle fleet, as well as the characteristics of the road network and the traffic plan applied, have generated increased needs for motorized travel. It is therefore interesting to establish a diagnosis of the current functioning of the road network in the city of Batna, for more effective management and to help planners anticipate the expected problems. This work will integrate an approach based on the association of the digital database with the use of Geomatics techniques (techniques based on the use of Geographic Information Systems) which can provide a powerful tool for better urban mobility.
\end{abstract}

Key words: Batna, urban roads, traffic, congestion, load, vehicles

\section{INTRODUCTION}

The transport sector is nowadays one of the essential factors for development. Roads, which facilitate the mobility of goods and people, are therefore one of the important factors for the development of the economy and prosperity in a country. According to the World Bank, there are 76 private vehicles per 1000 inhabitants in Algeria. As a result, it ranks fifth in Africa for the number of vehicles per capita (Benmahmoud, 2013).

It is important to note that the private vehicle has become the most widely used means of urban mobility, and public authorities must therefore "build an urban transport system in the sustainable sense of the term, as long as they develop a participatory approach and innovative communication at the same time" (Boubakour, 2008). 
Over the past twenty years, the Geographical Information System (GIS) has been an area of information and communication technology increasingly used by public authorities in decisionmaking, particularly in planning and management (Masser and Ottens, 1999; Jankowski, 2009; Stillwell et al., 1999).

Although GIS has been used for more than thirty years, however, it has only recently been used in the field of transport (Shafabakhsh et al., 2017; Sun et al., 2011; Morita et al., 2004; Ueda et al., 1996).

In this context, the present study is based on a series of questions related to the contribution of Geomatics to the management of the road network in the city of Batna.

A database and digital mapping of the road network were set up from a Geomatics perspective. The objective is to demonstrate the usefulness of GIS in road network management to enable coherent management of road mobility, thus facilitating the decision-making process by the concerned services.

\section{STUDY AREA}

Batna wilaya is located in the eastern part of Algeria in the Aurès region. The city of Batna is the capital of the wilaya located at the crossroads of Constantine, Biskra and Khenchela roads. Batna is considered as a crossroads that aims to ensure the interconnection of the regional regions of the north and south and at the same time to provide the East-West transition: Khenchela - Biskra (figure 1).

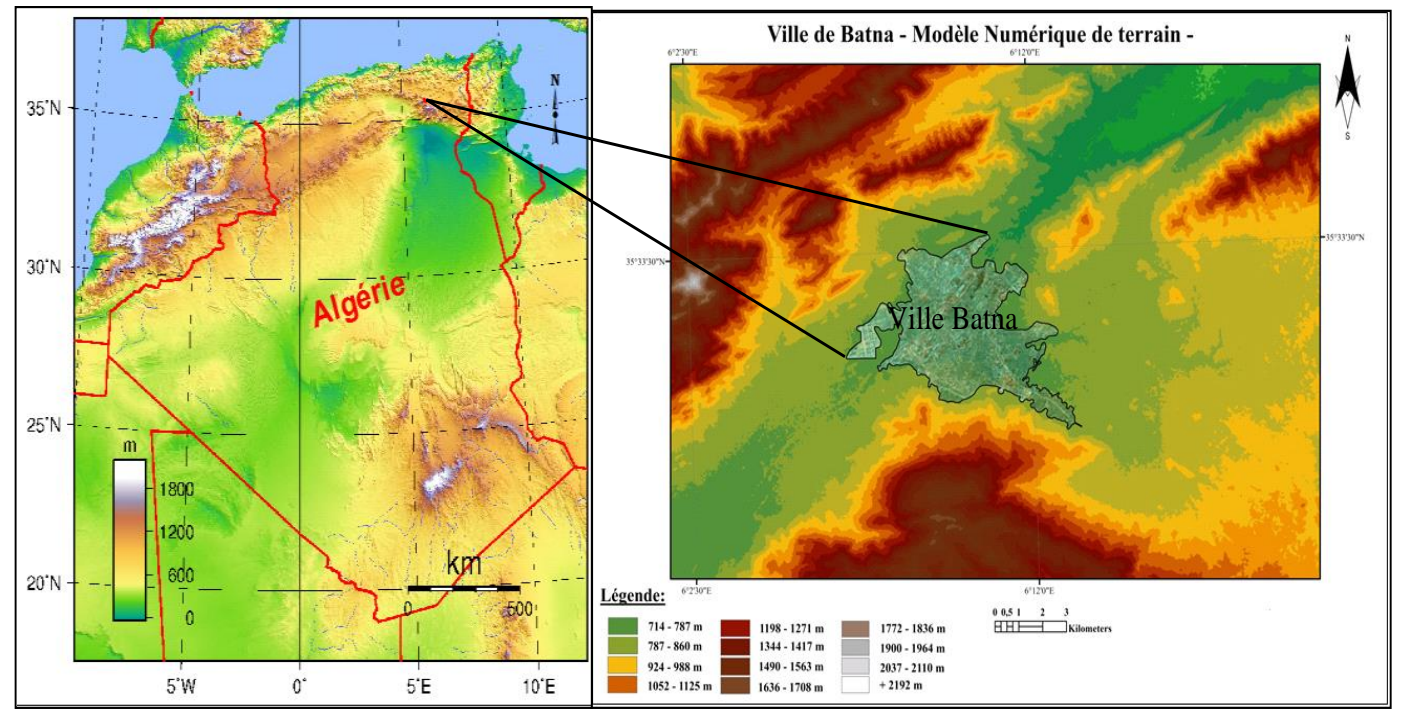

Figure 1. The geographical and administrative situation of Batna city Source: Merdassi Abdelmoumene

\section{MATERIALS AND METHODS}

The methodology used in this work is based on satellite data, topographical data, urban planning instruments and field surveys. These data are then integrated and analyzed in a GIS environment for road traffic restitution and analysis (table 3) using the software: ENVI 4.5 for image processing and ArcGis 10.1 for vector mode GIS.

The survey is based on the information collection for each primary urban road as follows:

- Number of vehicle fleets in the city;

- Present-day traffic conditions;

- Traffic variations during the day (especially during rush hours). 


\section{Urban evolution of the city}

The change detection approach helps to better assess the socio-spatial changes that occur in a region. To this end, the vectorization and superposition of the various multi-date classifications are an excellent source of information to determine the size and trend of urban dynamics in Batna City (figure 2).

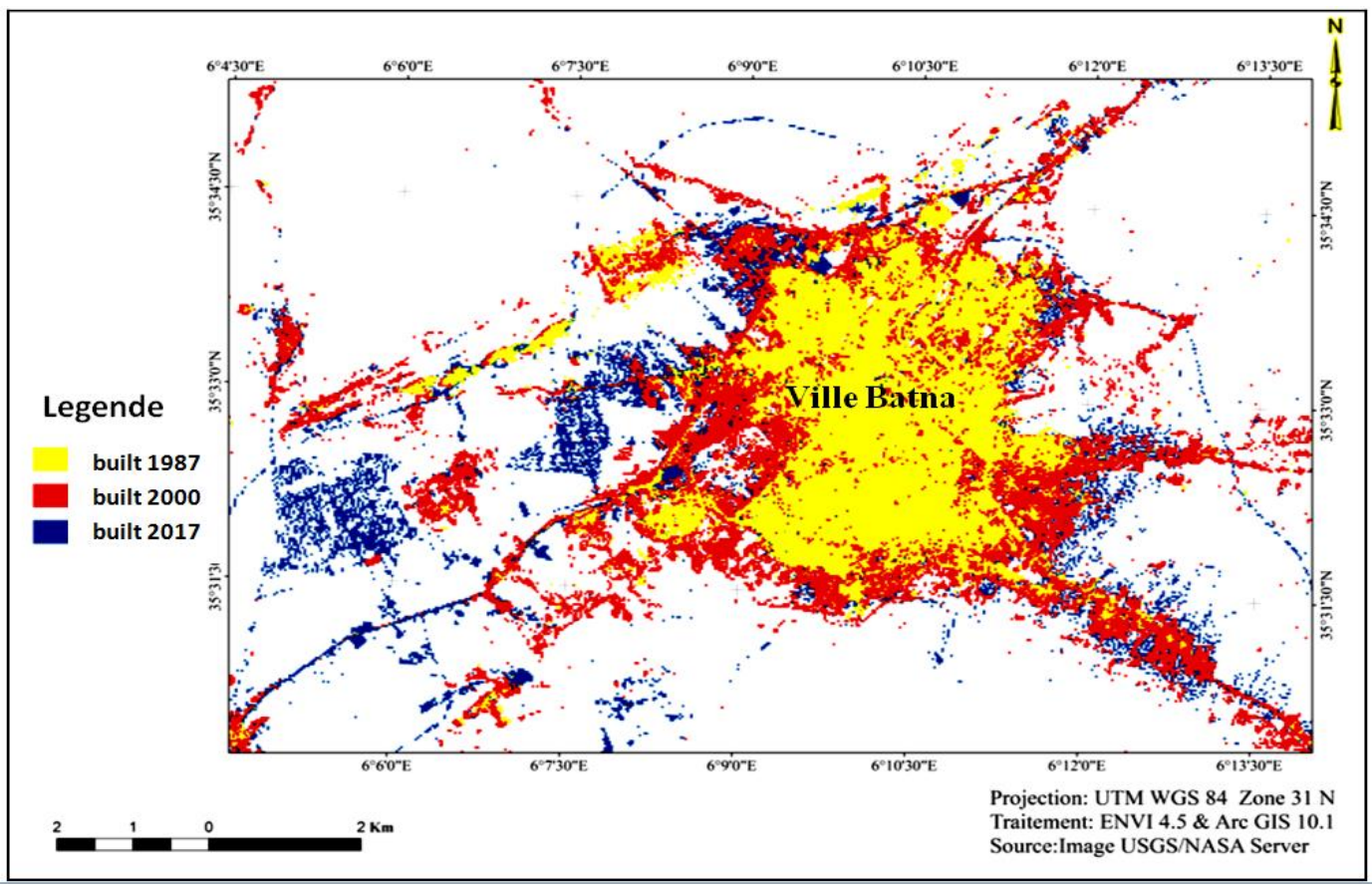

Figure 2. The evolution of the built environment in the Batna city in 1987, 2000 and 2017 Source: (Landsat images)

Table 1. Evolution of land use areas

\begin{tabular}{|c|c|c|c|c|c|c|}
\hline \multirow{2}{*}{$\begin{array}{c}\text { Land use } \\
\text { units }\end{array}$} & \multicolumn{2}{|c|}{ Classification1987 } & \multicolumn{2}{c|}{ Classification 2000 } & \multicolumn{2}{c|}{ Classification 2017 } \\
\cline { 2 - 7 } & $\begin{array}{c}\text { Surface in } \\
\text { hectares }\end{array}$ & Surface \% & $\begin{array}{c}\text { Surface in } \\
\text { hectares }\end{array}$ & $\begin{array}{c}\text { Surface } \\
\%\end{array}$ & $\begin{array}{c}\text { Surface in } \\
\text { hectares }\end{array}$ & Surface \% \\
\hline Urban space & 1021,41 & 12,00 & 1969,92 & 23,13 & 3706,38 & 43,53 \\
\hline Bare land & 2528,64 & 29,70 & 1998,18 & 23,46 & 1690,92 & 19,86 \\
\hline Forest & 1795,50 & 21,08 & 1517,67 & 17,82 & 2114,37 & 24,83 \\
\hline Farm land & 3168,90 & 37.21 & 3028,68 & 35,57 & 1002,78 & 11,77 \\
\hline
\end{tabular}

The analysis of the classification results (table 1) confirms the progression of the urbanized surface between the two periods. There was a development in the surface of the urban spot of 948.5 hectares or 67.75/year between 1987 and 2000. In the period between 2000 and 2017 this area developed with 1737.5 hectares or 115.75 hectares/year.

\section{Road network components in Batna}

The road network in Batna city consists of 3 types of roads (figure 3).

- City bypasses

These roads partially avoid the crossover of Batna city, except that the multiple traffic jams (due to poorly designed junctions, parking and reduced traffic flow at police checkpoints) discourage 
motorists from using them. They are supposed to prevent transit traffic from accessing the city and thus avoiding any congestion and safety problems that may arise.

These roads have a dual role: interurban connections and city bypasses.

- South bypass

It bypasses the urban area to the south along the protection ditch, to allow traffic between the two main roads, National No. 3 (RN3) and National No. 31 (RN31), towards Khenchela.

- North bypass

Biskra - Constantine: It borders successively the new urban housing zone II (ZHUN2), the Kechida neighborhood and the Industrial Zone. The development of the city on both sides also gives it an additional role as a collector road.

\section{Urban roads}

There are three types of urban roads:

- Primary roads

These roads provide access from the city center to the suburban districts; all these roads are structured by two major axes:

Axis 1: Boulevard KL, Route de Biskra, Avenue de l'Indépendance and Route de Constantine.

Axis 2: Avenue de la République, Rue Boukhlouf Mohamed and Allées Boudiaf Mohamed.

- Secondary roads

They are the second group of roads that connect neighborhoods from the main network.

- Tertiary roads

The tertiary roads provide access within the properties. They have been delayed in terms of planning.

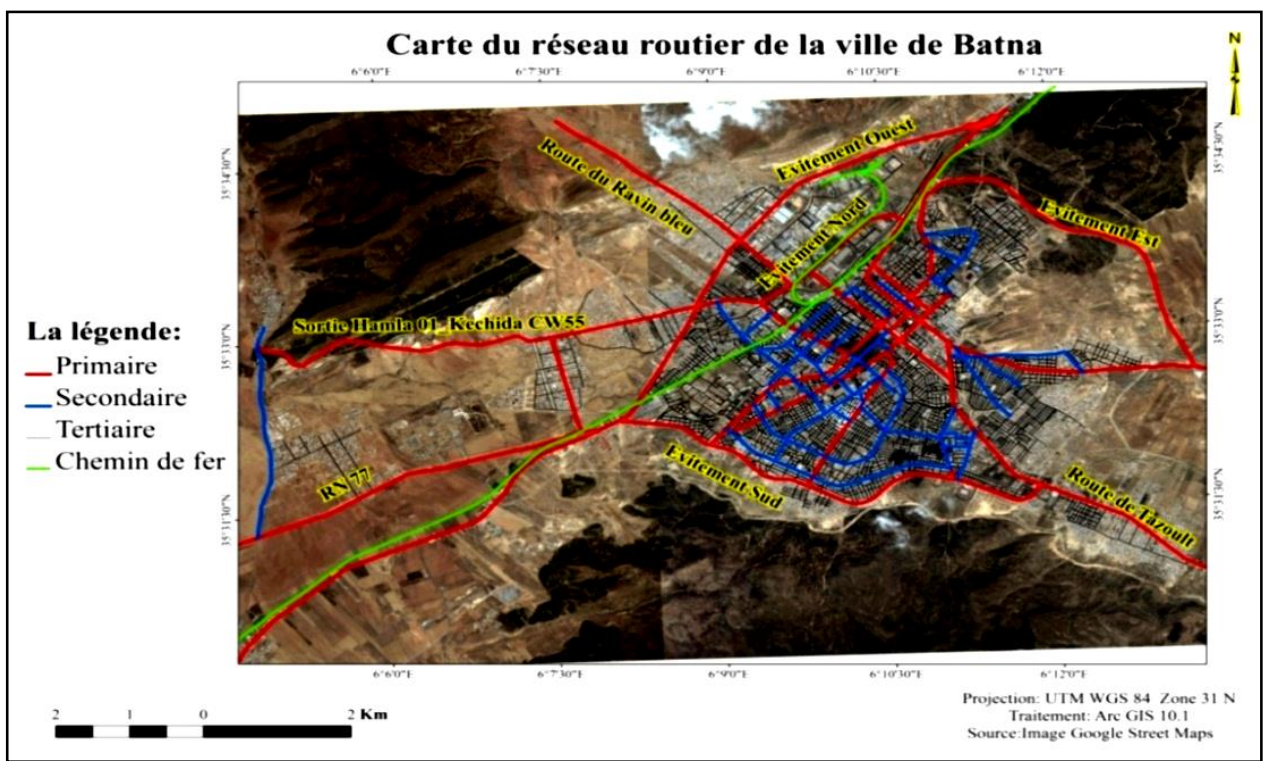

Figure 3. Batna city road network (2017) Source: Google Maps

\section{Current functioning of the road network}

Pendulum movement for the employment sector in Batna

As shown in table 2, there is a real pendulum migration between Batna and the neighbouring cities. In this example, public transport is taken into account since it is often considered as a means of transport for work-related or service purposes. 
Table 2. Number of travelers at departure and arrival (Bus transport)

Source: 2016 Urban Community Plan

\begin{tabular}{|c|c|c|}
\hline City & Departures & Arrival \\
\hline Batna & 2038 & 10701 \\
\hline
\end{tabular}

It is clear that the number of passengers arriving in Batna by public road transport is higher than the number leaving Batna, which confirms the attractiveness of Batna city.

\section{Theoretical and operational capacity of roads}

Road capacity at a given point is the maximum number of vehicles that can be passed at that point during a reference time interval, usually corresponding to an hour (Wardrop, 1954) and depending on the existing infrastructure and traffic characteristics.

Capacity on a road route is a different concept defined by Cohen's (2005) quotation: "Capacity on a route is the minimum of capacity at each of its points".

- Theoretical capacity

The theoretical capacity of a road section is the maximum traffic intensity per hour. It is calculated based on the maximum number of passenger cars passing through in 15 minutes, multiplied by the coefficient corresponding to the peak hour. This number is not an absolute maximum; it is based on reasonable respectability. Thus expressed, capacity depends only on the number of lanes, their width and off-road areas and the gradient of the section (PIARC, 2011).

In this case, every $1000 \mathrm{~m}$ with a vehicle width of $5 \mathrm{~m}$ is equal to 200 :

$$
\boldsymbol{T} \boldsymbol{c}=200{ }^{x} \text { road width }
$$

- Practical capacity

Practical capacity is defined as the maximum observable traffic intensity on the section, depending on the nature of the traffic predominating at that point (PIARC, 2011).

- Saturation Flow Rate (SFR) as follows:

The saturation flow rate of a roadway, whether in the morning or in the evening, is calculated

$$
\boldsymbol{S F R}=\text { load }(P P V / h) \times 100 / \text { theoretical capacity }
$$

Where, PPV is the Private Passenger Vehicle unit.

Table 3 summarizes the main characteristics of the road load survey on the main roads of the city.

Table 3. Database component

\begin{tabular}{|c|c|c|c|}
\hline $\begin{array}{c}\text { Sectors } \\
\text { and population }\end{array}$ & Equipment & Urban transport line & Road \\
\hline Code & & & Code \\
Sector name & & Code & Name \\
Surface area & Code & Origine & Length \\
Ranking & Type & Destination & Width \\
Percentage & Name & Outward length & Load HPM \\
Population87 & Sector & Number of stops & LoadHPS \\
Density 87 & Equipment & Return width & Daily capacity \\
Population 98 & Surface area & Number of stops & Exploitation \\
Density 98 & & Busnumber & Condition \\
Population 2014 & & Places available & Theoretical capacity \\
Density 2014 & & & Saturation rate travel time \\
& & & Speed \\
\hline
\end{tabular}


Using this database, queries can be made to analyze the state of the place. This feature allows highlighting the real issues in the field. The example given in this article concerns the saturation of the current roads. In addition, several requests can be made depending on the factors having a direct impact on traffic, allowing several special analyses to be performed.

\section{RESULTS AND DISCUSSION}

\section{Analysis of the practical load of roads}

Suburbanization and more generally, any separation of the workplace and the place of residence have led to significant migration (daily movement between the city dweller's home and his place of work, always at the same times). In addition, service and commercial transport generates significant traffic on the city's roads.

The road network in the city of Batna is experiencing significant traffic but has not reached saturation levels yet (figure 5).

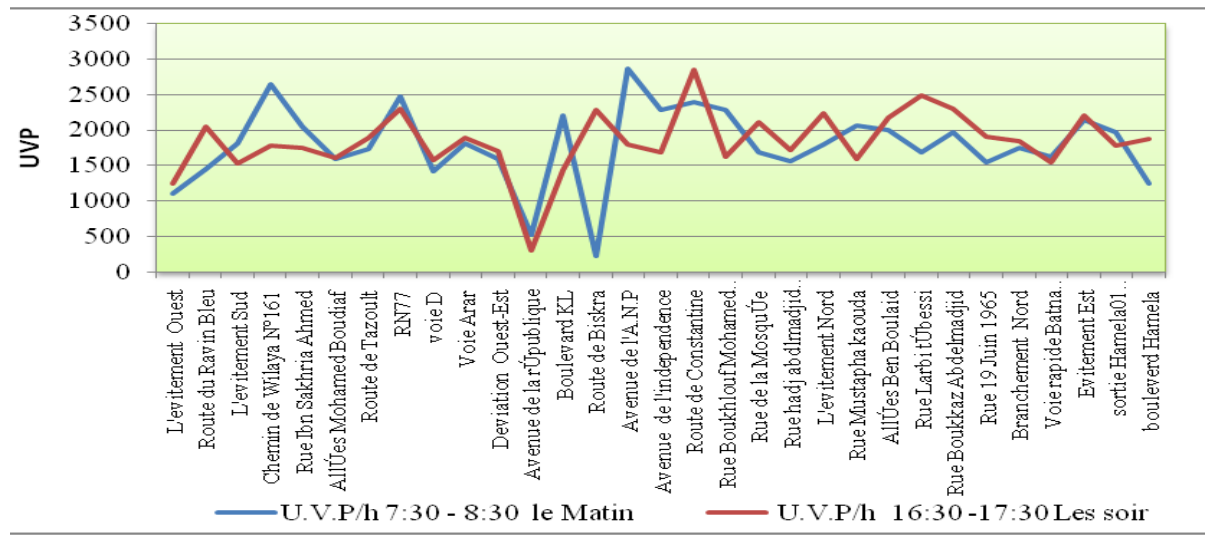

Figure 5. Load of the main axes (morning and evening)

It can be noticed that the highest load at Morning Rush Hour is observed at A.N.P. Avenue (2867 U.V.P/MRH), and the highest load at Evening Rush Hour is observed at Constantine Road (2851 U.V.P/ERH). Roads with a low load are: Biskra road with a load of (220 U.V.P/MRH) in the morning and Avenue de la République with a charge of (298 U.V.P/ERH) in the evening.

Comparison between the theoretical capacity and the practical load of the different primary axes

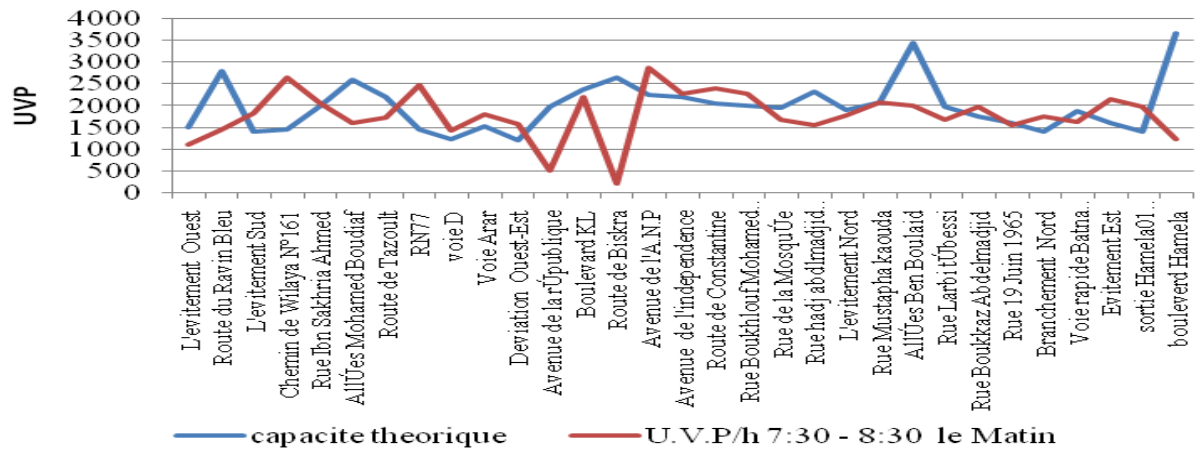

Figure 6. Theoretical and practical load at morning rush hour 
The road network in the city of Batna has experienced significant traffic but has not reached saturation levels. This traffic is observed on various routes such as those connecting the city of Batna to the surrounding areas.

Access to the city center is characterized by very high mechanical traffic pressure, which shows a permanent load that is constantly generated on downtown roads on a daily basis. It can also be noticed that during rush hours, there is acongestion on the wilaya road $\mathrm{N}^{\circ} 161, \mathrm{RN} \mathrm{N}^{\circ} 77$, avenue de l'A.N.P, as well as the rue de Bouakaz and the east bypass, which explains that the majority of the practical load is caused by the entrances to the city of Batna and is higher than the theoretical load (figure 6).

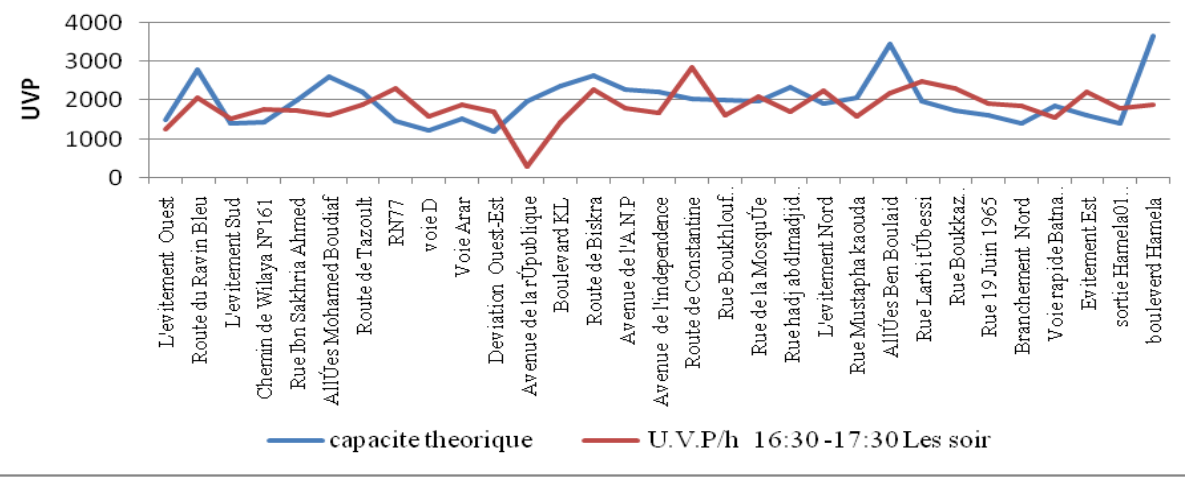

Figure 7. Theoretical and practical load at the evening rush hour

It can be seen that the presence of bus and taxi stations on general traffic lanes disrupts the traffic flow. The inconvenience is caused by traffic on the boulevards and highways with very heavy commercial activity that are parked on both sides.

\section{Analysis of the saturation rate of the primary axes}

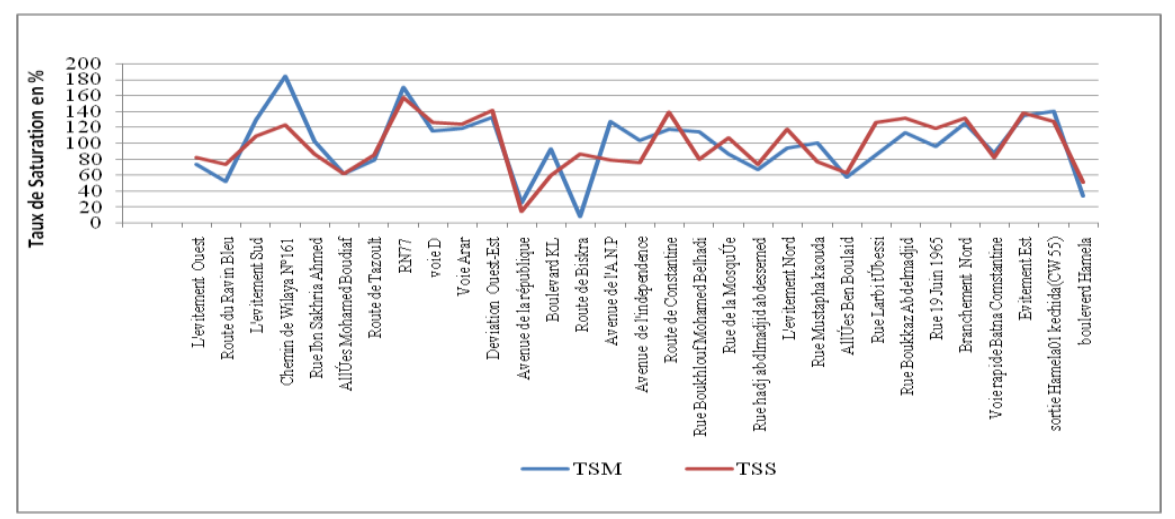

Figure 8. Saturation rate of the main axes (morning and evening)

The city, which currently hosts almost twice its capacity, is in a state of major traffic jams. Some sections have a very high saturation rate, including several axes that have a rate higher than $100 \%$ in the morning and evening rush hours.

It is can be noticed that National Road $\mathrm{N}^{\circ} 3$ (CW N 161 in this scale) has a very high saturation rate of $183.75 \%$ in the morning and $123.19 \%$ in the evening (figure 8). 


\section{Transport hubs}

The importance of certain facilities or their absence results in significant population movements from one sector to another and from one agglomeration to another.

Traffic black spots are caused by traffic management malfunctions due to factors external to the road network and its management, such as the presence of certain very specific problems on the network that can create waiting lines over several hundred meters. The traffic black spots observed in the city of Batna are summarized in Figure 9.

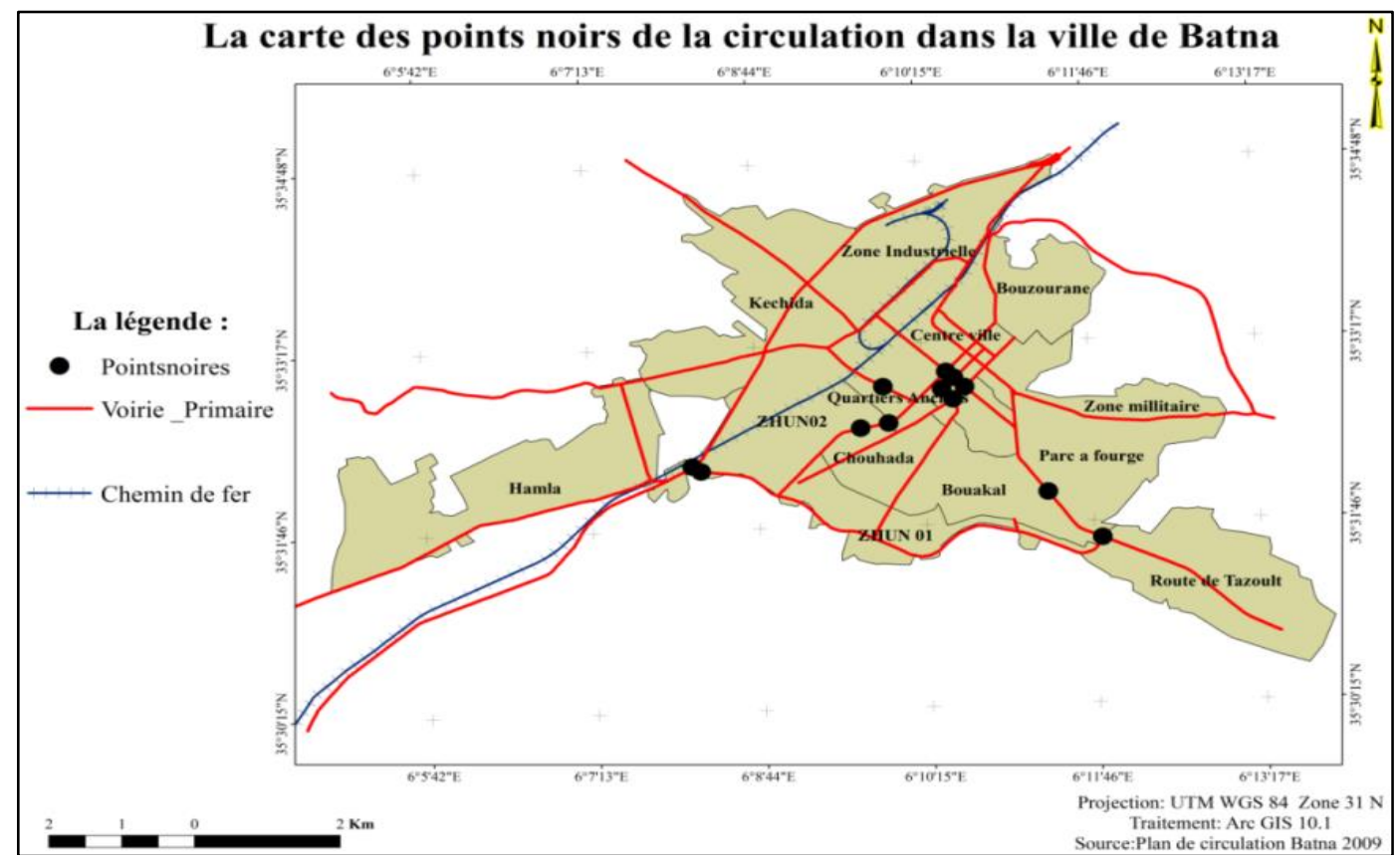

Figure 9. Traffic black spots in the city of Batna

The perimeter of the city of Batna includes places of economic attraction and a series of facilities and structuring activities. Therefore, it has been noticed that the traffic squares are located at the crossroads (roundabouts) as well as the black spots are much more centered in the city center, and this corresponds to the concentration of the various life services, which causes a great accessibility problem and consequently long lines of cars. As a result, it is difficult for many buses to cross these lines.

The two black spots on the M. Boudiaf alleys are the cause of the presence of the CHU (Centre Hospitalier Universitaire - University Hospital).

The saturation of all these intersections is the result, in addition to their presence on hightraffic roads, of the accumulation of certain causes of dysfunction linked to several factors.

A better management of urban roads by geographic information systems (GIS) requires a reliable and enriched database that allows analyzing, managing and interpreting the results obtained from the different requests.

The analyses carried out show that most of the city's road network, and in particular the city center and the first suburbs of urban fabric, are relatively saturated, particularly during rush hour.

This lack of traffic flow is the result of a constant increase in the number of private vehicles combined with undersizing of the primary and secondary roads. There are roads that have a morning and evening saturationrate of $>100 \%$. 


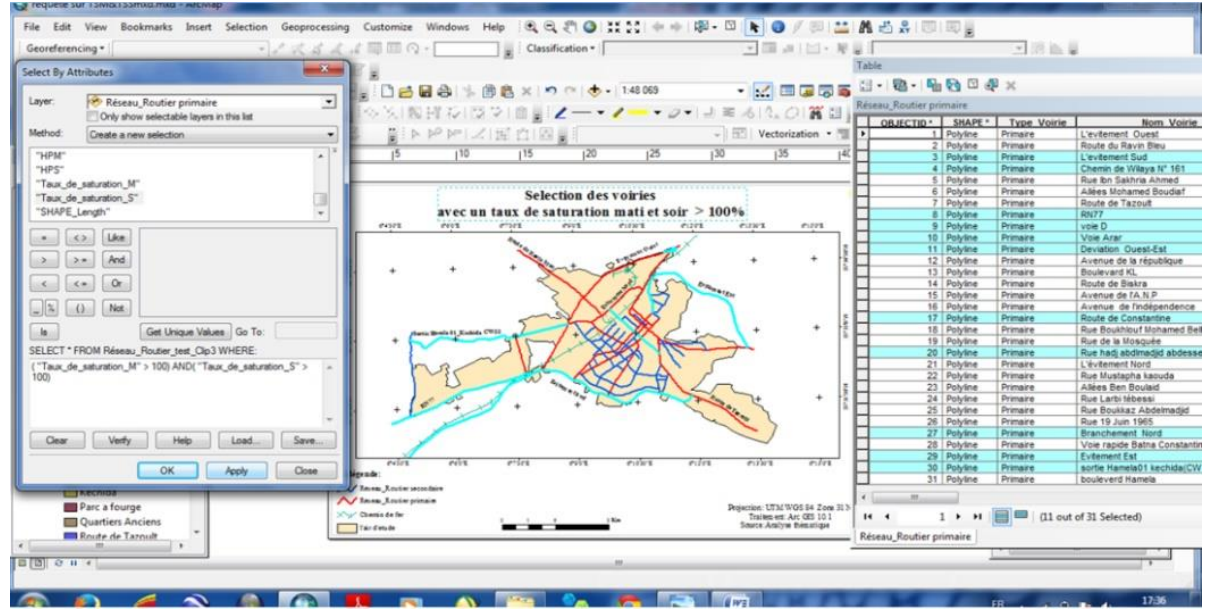

Figure 10. Selection of roads with MSR and ESR $>100 \%$

MSR $=$ Morning Saturation Rate

$\mathrm{ESR}=$ Evening Saturation Rate

These axes are characterized by:

- Narrow roadway that causes lateral collisions;

- Number of incoming channels that are too high;

- Does not have traffic lights (Lack of signage);

- Anarchic (informal) parking;

- Conflicts: vehicle/pedestrian, vehicle/vehicle;

- Congestion almost all day long;

- Reduced visibility distance when approaching the intersection;

- High population density and where illegal constructions proliferate;

- Poor road conditions;

- Sidewalks congested by informal transport;

- No pedestrian crossing;

- Inadequate width and number of rows;

- Incoherence of the layout in relation to the typology of the track;

- The heavyweight;

- Poor layout of roundabouts, sidewalks congested by informal transport (Fraud);

- Input radius too large;

- Almost no ground markings for user guidance.

\section{RECOMMENDATIONS}

To improve the situation, a series of measures have been proposed for the rehabilitation of roads. The solutions that can be proposed are:

- Installation of traffic lights;

- Widening of the roadway for any axis;

- Regular maintenance of the pavement;

- Improvement of the perception of mini roundabouts;

- Installation of speed limitation road signs;

- Any arrangement to reduce the approach speed (narrowing of the pavement width has crossed;

- Reduce the width of the inlets and outlets;

- Closeness of pedestrian crossings to the intersection area;

- Parking management;

- Presence of bus and taxi stations on the traffic lanes. 


\section{CONCLUSION}

A better management of urban roads by geographic information systems (GIS) requires a reliable and enriched database that allows analyzing, managing, and interpreting the results obtained from the different requests.

The city of Batna is a medium-sized city that is undergoing a development towards a form of metropolis due to a spreading development. This urban development, driven by both population growth and migration within and between wilayas (departments), has created new travel needs.

Road infrastructure and the transport network have not been able to handle traffic flow, especially during rush hours. This situation of permanent road congestion is a major problem for the social and economic development of the city and raises serious environmental problems.

The use of the database made it possible to highlight saturation levels, fluidity levels and service rates. All these elements make it possible to first target the sectors to be maintained and redeveloped as a priority. In a second step, the study addressed the problem of conflict points by analyzing intersections (crossroads and roundabouts).

As a result the analysis showed a malfunction in traffic that result in daily traffic jams. There is also a lack of prospective visions in terms of urbanization, particularly during the postcolonial period.

Therefore, a traffic plan must be implemented to ensure the adequate traffic flow and to ensure a service for marginalized sectors. Finally, it is important to take into consideration future urban development and the population' most convenient means of transportation.

\section{REFERENCES}

Benmahmoud, K. (2013). Faible taux de motorisation Motors.

Boubakour, F. (2008). Les transports urbains en Algérie face aux défis du développement durable: sur les problèmes rencontrés et les solutions proposées. Paper presented at the CODATU XIII.

Cohen, S. (2005). Systèmes et méthodes de détection automatique des incidents routiers: guide technique. INRETS.

Jankowski, P. (2009). Towards participatory geographic information systems for community-based environmental decision making. Journal of Environmental Management, 90(6), 1966-1971.

Masser, I., \& Ottens, H. (1999). Urban Planning and Geographic Information Systems In: Stillwell J, Geertman S, Openshaw $S(e d s)$ Geographical Information and Planning: European Perspectives. Springer Berlin Heidelberg, Berlin, Heidelberg, p. 25-42.

Morita, A., Takeuchi, K., Doi, K., Sigua, RG., Honda, K., Seta, F., \& Murakami, A (2004). Urban transport and local governance in asian developing countries: In Search of Transport Policies (IATSS H493 Project Report). IATSS Research 28 (1). p. 6-18.

Piarc, WRA (2011). Road Tunnels Manual.

Shafabakhsh, G.A., Famili, A., \& Bahadori, M.S. (2017). GIS-based spatial analysis of urban traffic accidents: Case study in Mashhad, Iran. Journal of Traffic and Transportation Engineering (English Edition), 4(3), 290-299.

Stillwell, J., Geertman, S., \& Openshaw, S. (1999). Geographical Information and Planning: European Perspectives. Springer Berlin Heidelberg,

Sun, J., Liu, Q., \& Peng, Z. (2011). Research and Analysis on Causality and Spatial-Temporal Evolution of Urban Traffic Congestions-A Case Study on Shenzhen of China. Journal of Transportation Systems Engineering and Information Technology, 11(5), 86-93.

Ueda, T., Nakamura, H., \& Shimizu E. (1996). GIS Integrated System for Urban Transport and Development Planning. In: Hayashi Y, Roy J (eds) Transport, Land-Use and the Environment. Springer US, Boston, MA, p. 317-336.

Wardrop, J.G. (1954). The Capacity of Roads. OR 5 (1), 14-24.

Submitted:

May 12, 2019
Revised:

Aprile 07, 2020
Accepted and published online August 10, 2020 